\title{
Neurogenic Locus Notch Homolog Protein 3 Staining Method
}

National Cancer Institute

\section{Source}

National Cancer Institute. Neurogenic Locus Notch Homolog Protein 3 Staining Method. NCl Thesaurus. Code C122869.

An immunohistochemical technique used to detect the presence of neurogenic locus notch homolog protein 3 in a tissue sample. 